\title{
Open peroral endoscopic myotomy for refractory benign esophageal stricture
}

A 36-year-old woman suffered thoracic pain and dysphagia following a barbecue 6 months earlier. Gastroscopy showed an ulcer in the lower esophagus. The thoracic pain disappeared after taking proton pump inhibitors (PPIs) for a week, but dysphagia continued. Repeat gastroscopy showed a thickened and rigid lower esophageal wall and esophageal stricture ( $\triangleright$ Fig. 1 a). The stricture was about $4.0 \mathrm{~cm}$ from the cardia. Endoscopic biopsy diagnosed inflammation. Esophagography showed severe stricture in the lower esophagus (> Fig.2a). Thoracic computed tomography showed a thickened lower esophageal wall, and endoscopic ultrasonography showed thickening of the muscularis propria in the lower esophagus ( $>$ Fig. 3), without manifestation of tumors. The patient continued to take PPIs and underwent three sessions of endoscopic dilation, without success; she lost $8.0 \mathrm{~kg}$ in weight.

We performed open peroral endoscopic myotomy (O-POEM) (-Video 1). The mucosal and circular muscle layers of the stricture were incised completely without submucosal tunnel creation ( Fig.4), and with the upper and lower edge incisions extending about $2.0 \mathrm{~cm}$ beyond the stricture.

The patient recovered uneventfully after endoscopic treatment and gradually returned to a normal diet. Her body weight had increased by $4.0 \mathrm{~kg}$ at 6 months after treatment. Follow-up esophagography showed that the stricture had significantly improved post-procedure ( $\mathbf{F i g . 2} \mathbf{b}$ ). Follow-up gastroscopy showed that the original esophageal incision had healed well and the lumen was only mildly strictured ( $\triangleright$ Fig.1 b), with smooth passage of the endoscope.

Endoscopic balloon dilation [1] or stenting [2] is an effective treatment for benign esophageal stricture. Radial incision and cutting [3] can also be performed. Due to the poor effect of balloon dilation, the rigid wall, and the presence of stricture, we performed O-POEM for this

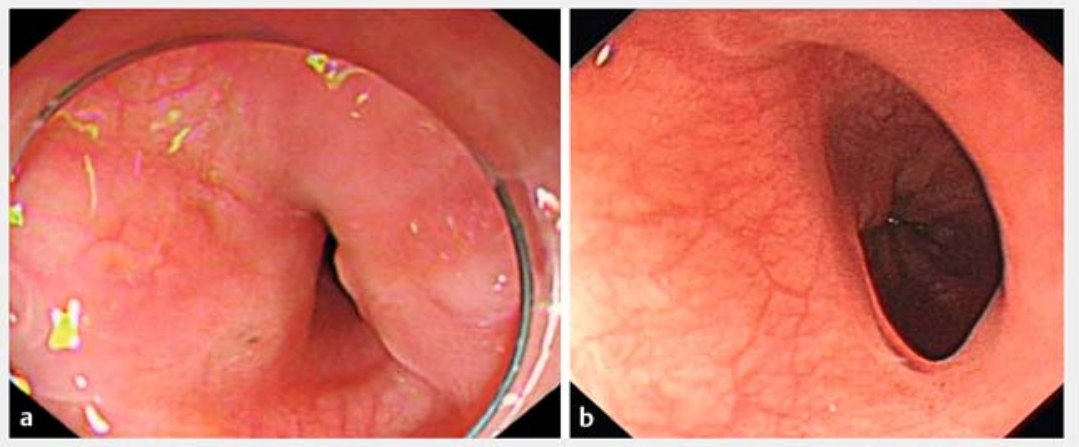

- Fig. 1 Gastroscopy. a Pre-procedure, showing a thickened and rigid lower esophageal wall and a stricture. $\mathbf{b}$ At follow-up, showing that the incision had healed well, with only mild stricture remaining.
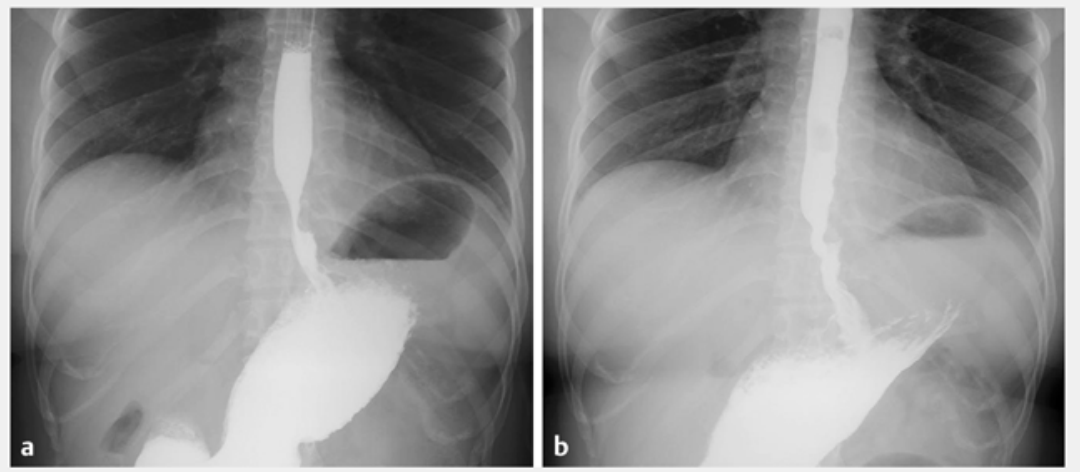

- Fig. 2 Esophagography. a Pre-procedure, showing severe stricture of the lower esophagus. b At follow-up, showing significant improvement, with only mild stricture.

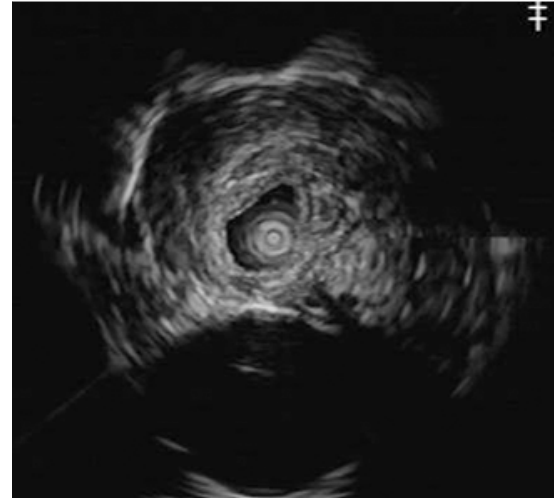

Fig. 3 Endoscopic ultrasonography showed a thickened muscularis propria in the lower esophagus.

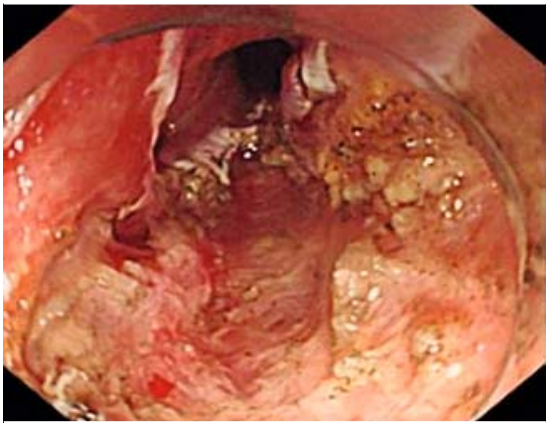

Fig. 4 The mucosal and circular muscle layers of the stricture were incised completely without submucosal tunnel creation. 


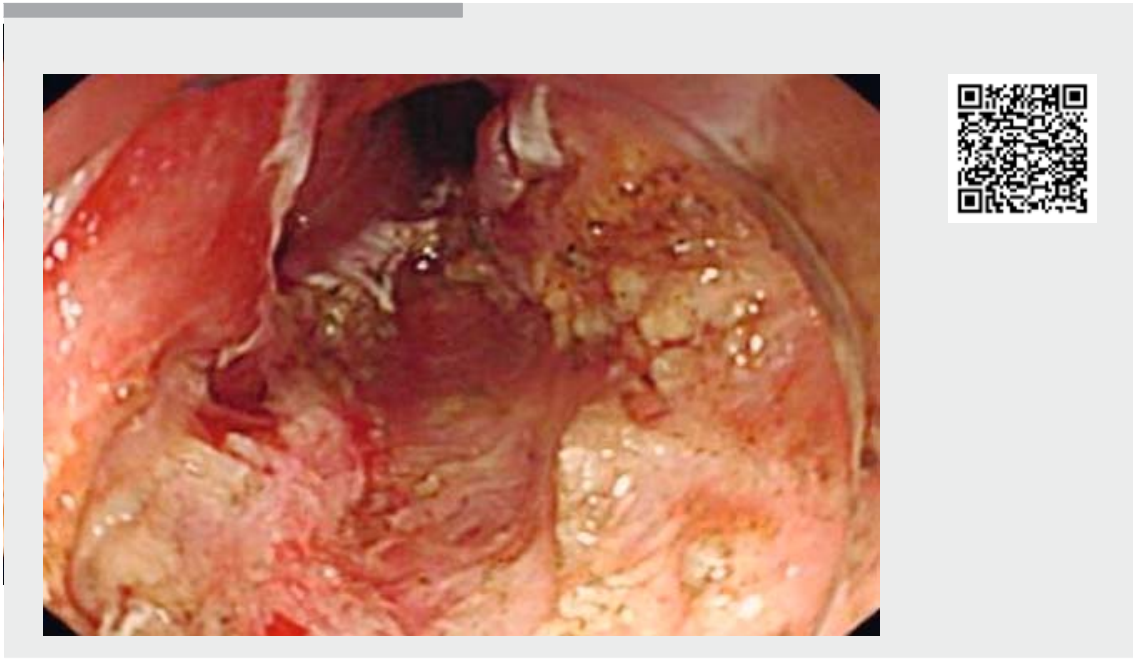

Video 1 The lower esophagus was rigid and strictured, and the mucosal and circular muscle layers of the stricture were incised completely without submucosal tunnel creation.

patient. O-POEM is a safe and effective treatment for achalasia [4], as well as an effective therapy for benign esophageal stricture.

Endoscopy_UCTN_Code_TTT_1AO_2AN

Funding

Sichuan Province Science and Technology Department (China)

$2018 S Z 0134$

The authors thank Sichuan Province Science and Technology Department (China) (2018SZ0134) for their support.

\section{Competing interests}

The authors declare that they have no conflict of interest.

\section{References}

[1] Osuga T, Ikura Y, Hasegawa K et al. Use of endoscopic balloon dilation for benign esophageal stenosis in children: our 11 year experience. Esophagus 2018; 15: 47-51

[2] Dall'Oglio L, Caldaro T, Toschia F et al. Endoscopic management of esophageal stenosis in children: new and traditional treatments. World J Gastrointest Endosc 2016; 8: 212-219

[3] Mizusawa T, Kobayashi M, Terai S. Radial incision and cutting for refractory benign esophageal stricture. Dig Endosc 2019; 31: e46-e47

[4] Liu W, Zeng HZ, Yuan XL et al. Open peroral endoscopic myotomy for the treatment of achalasia: a case series of 82 cases. Dis Esophagus 2019; 32: 1-7

Bibliography

DOI https://doi.org/10.1055/a-1089-7551

Published online: 29.1.2020

Endoscopy 2020; 52: E271-E272

(c) Georg Thieme Verlag KG

Stuttgart · New York

ISSN 0013-726X

1 Department of Gastroenterology, West China Hospital, Sichuan University, Chengdu, Sichuan, China

2 Department of Pediatrics, West China Second University Hospital, Sichuan University, Chengdu, Sichuan, China

\section{Corresponding author}

\section{Bing Hu, MD}

Department of Gastroenterology, West China Hospital, Sichuan University, No. 37 Guo Xue Xiang, Chengdu, Sichuan, 610041, China

Fax: +86-28-85423387

hubingnj@163.com

\section{ENDOSCOPY E-VIDEOS}

https://eref.thieme.de/e-videos

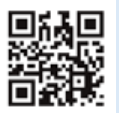

Endoscopy E-Videos is a free access online section, reporting on interesting cases and new

techniques in gastroenterological endoscopy. All papers include a high quality video and all contributions are freely accessible online.

This section has its own submission website at https://mc.manuscriptcentral.com/e-videos

\footnotetext{
* These authors contributed equally to this work.
} 